\title{
Toxoplasmose em cães co-infectados com o vírus da cinomose
}

\section{Toxoplasmosis in distemper virus infected dogs}

\author{
Leandro d'Arc Moretti ${ }^{1 *}$; Tatiana Evelyn Ueno ${ }^{1}$; Márcio Garcia Ribeiro²; \\ Daniel Moura Aguiar ${ }^{3}$; Antonio Carlos Paes²; \\ Sandia Bergamaschi Pezerico ${ }^{4}$; Aristeu Vieira da Silva ${ }^{5}$
}

\begin{abstract}
Resumo
Relatam-se quatro casos de toxoplasmose em cães, evidenciando-se a sintomatologia nervosa indistinguível daquela causada pela cinomose de forma isolada e mostrando a ocorrência concomitante das duas enfermidades. Sugere-se que os dados de anamnese, como hábitos de carnivorismo e contato com gatos, aliados a sinais clínicos como linfadenopatia, pneumonia, secreção ocular purulenta e distúrbios neurológicos, favoreçam a suspeita clínica de toxoplasmose. Propõe-se um tratamento, preventivo para a toxoplasmose, nos cães com cinomose, baseado nas condições de diagnóstico disponíveis pelo clínico.
\end{abstract}

Palavras chave: Cães; Toxoplasmose; Cinomose; Sinais neurológicos

\begin{abstract}
This report shows four cases of dog's toxoplasmosis, pointing that the neurologic signalment of toxoplasmosis and distemper is quite indistinguishable. The anmnestic data of flesh-eating and cat contact is linked with easier suspect of toxoplasmosis, reinforced by the presence of linfadenopathy, pneumonia and neurologic signs. A treatment proposal is offered, being a preventive measure to toxoplasmosis in distemper dogs, according to the clinician diagnostic conditions.
\end{abstract}

Key words: Dogs; Toxoplasmosis; Distemper; Neurological signalment

\section{Introdução}

A toxoplasmose é uma doença de caráter zoonótico, decorrente da infecção dos animais e do homem pelo protozoário coccídeo do filo Apicomplexa, espécie Toxoplasma gondii. Mais de 300 espécies de mamíferos e aves podem ser parasitadas, o que aliado à distribuição ubíqua do agente e à infectividade de todas as formas evolutivas do parasito, torna elevada a prevalência de infecção (CORRÊA; CORRÊA, 1992; KAWAZOE, 1995).

A transmissão de T. gondii para os homens e animais ocorre principalmente pela ingestão de alimentos contaminados por fezes de felídeos e ocasionalmente de leite contendo taquizoítos, ou por via

\footnotetext{
1 Residentes da disciplina de Enfermidades Infecciosas dos Animais da FMVZ-UNESP-Botucatu, Médico Veterinário graduado em 2000 pela Universidade Federal de Lavras - MG. Email: lmoretti@ig.com.br

2 Docentes da disciplina de Enfermidades Infecciosas dos Animais da FMVZ-UNESP-Botucatu

3 Mestrando em Ciências Biomédicas (Biologia da Relação Hospedeiro-Parasita) do ICB-USP-São Paulo

4 Mestranda em Doenças Tropicais (Biologia Tropical) da FM-UNESP-Botucatu

5 Doutorando em Doenças Tropicais (Biologia Tropical) da FM-UNESP-Botucatu

* Autor para correspondência
} 
transplacentária (TENTER; HECKEROTH; WEISS,2000). Além destas formas de transmissão, destaca-se o papel do carnivorismo no aumento da prevalência da infecção nas diferentes espécies animais acometidas (DUBEY, 1977; KAWAZOE, 1995).

A transmissão da toxoplasmose para os seres humanos pela lambedura de cães infectados é objeto de controvérsia entre os autores (DUBEY; BEATTIE, 1998;. TENTER; HECKEROTH; WEISS, 2000). Esta via já foi aventada na veiculação do agente entre seres humanos (KAWAZOE, 1995) e mesmo considerando-se o aspecto zoonótico através de cães. Apesar desta via já ter sido considerada de baixo risco na propagação da doença (TENTER; HECKEROTH; WEISS;2000), estudos recentes têm apontado a urina e a saliva como importantes fontes de infecção (BRESCIANI et al., 2001).

A ocorrência da toxoplasmose no homem tem sido associada às doenças imunossupressivas, reconhecida como importante causa de morte em pacientes com câncer e, a partir da década de 80, em pessoas acometidas pela síndrome da imunodeficiência adquirida - aids (MARTINS; VIANA, 1998). A imunossupressão torna o hospedeiro mais susceptível à proliferação do T. gondii, em virtude do caráter oportunista do parasito. De maneira similar, em cães é freqüente a descrição da toxoplasmose em animais apresentando enfermidades imunossupressivas, incluindo a ehrlichiose e a cinomose (DUBEY; LAPPIN, 1998). Segundo Dubey e Beattie (1998) a associação de cinomose e toxoplasmose ocorre em $99 \%$ dos casos clínicos relatados da protozoose.

A taxa de infecção da toxoplasmose difere da atribuída à doença, pois como a distribuição do agente é ampla no ambiente há grande risco de infecção (DUBEY; BEATTIE, 1998). Vários autores já demonstraram que a toxoplasmose também está difundida entre os cães no Brasil (GERMANO; ERBOLATO; ISHIZUKA, 1981; ISHIZUKA; YASUDA, 1981; NAVARRO et al., 1997; GUIMARÃES et al., 1992; BRITO et al., 2002). No entanto, a doença no cão é de difícil diagnóstico, porque a en- fermidade, em geral, é de evolução crônica (NAVARRO et al., 1997), decorrente da alta infectividade e baixa patogenicidade do parasito (BRITO et al., 2002). A ampla ocorrência de infecção deve ser levada em consideração na ocasião de interpretação dos diferentes testes sorológicos para o diagnóstico da toxoplasmose. Assume-se evidência de infecção ativa na presença de um aumento de quatro a oito vezes no título, observado em amostras séricas tomadas com duas a quatro semanas de intervalo, ou com o título único maior ou igual a 1000 no teste de imunofluorescência indireta (DUBEY, 1977).

As manifestações clínicas da toxoplasmose são muito variadas e comuns a diversas enfermidades, com envolvimento de vários órgãos e sistemas incluindo gastrintestinal, linfático, esplênico, hepático, pulmonar, osteomuscular, cardíaco, ocular e nervoso (DUBEY, 1977; DUBEY; LAPPIN, 1998). O tipo e magnitude da sintomatologia clínica dependem da localização e grau de lesão tecidual, que se deve à ocorrência de necrose determinada pelo caráter intracelular do parasito (CORRÊA; CORRÊA, 1992; DUBEY; LAPPIN, 1998).

Os sinais clínicos generalizados são observados com maior freqüência em cães com menos de um ano de idade. No entanto, nesta faixa etária os principais sinais clínicos são neuromusculares. Em infecções decorrentes da ingestão de cistos teciduais ou oocistos, ocorre diarréia e vômito decorrentes da necrose determinada pelos taquizoítos, principalmente no intestino e nos órgãos linfóides associados. Em seguida, o protozoário dissemina-se por via hemática e/ou linfática, determinando necrose focal em vários órgãos (DUBEY; LAPPIN, 1998). O envolvimento linfático provoca linfadenopatia, referida como a manifestação clínica mais freqüente na toxoplasmose adquirida nos cães (ABREU et al., 1999b). As lesões provocadas pelo agente em linfonodos e baço ocasionam imunossupressão, com diminuição de g globulinas (CORRÊA; CORRÊA, 1992). A lesão hepática determina hipoproteinemia, hipoglobulinemia, aumento das atividades enzimáticas séricas de alanina amino transferase 
(ALT), fosfatase alcalina (FA), aumento nos níveis séricos de bilirrubina, icterícia e efusão peritoneal (DUBEY; LAPPIN, 1998).

T. gondii induz necrose pulmonar, levando a pneumonia e dispnéia, embora em muitos casos, a pneumonia seja decorrente da co-infecção com outros agentes, especialmente o vírus da cinomose (DUBEY, 1977). As lesões musculares por T. gondii determinam hiperestesia à palpação, marcha rígida, claudicação e aumento da atividade sérica enzimática de creatinina quinase. Arritmias e insuficiência cardíaca também podem desenvolver-se devido ao envolvimento miocárdico (DUBEY; LAPPIN, 1998).

Os sinais nervosos da toxoplasmose dependem da localização do parasito no cérebro, cerebelo e medula espinhal. A multiplicação do agente nestes locais leva a episódios convulsivos, déficits de nervos cranianos, ataxia, tremores, paresias e paralisias (DUBEY; LAPPIN, 1998). Ocasionalmente ocorre mudança de hábitos, com desenvolvimento de apatia ou agressividade. Entretanto, os sinais nervosos predominantes da toxoplasmose são paresia e paralisia de membros posteriores (CORRÊA; CORRÊA, 1992).

Em cães, as lesões oftálmicas incluem uveíte anterior, iridociclite, hiperplasia do epitélio ciliar, retinite, coroidite, miosite extra-ocular, esclerite, episclerite e neurite óptica (ABREU et al., 1999a; DUBEY; LAPPIN, 1998; MARTIN; STILES, 1998).

Este trabalho tem como objetivos abordar vários fatores relacionados com a toxoplasmose em cães, enfatizando a sintomatologia neurológica como principal acometimento, a cinomose como evento predisponente e discutindo a abordagem diagnóstica e terapêutica baseada na disponibilidade de exames complementares.

\section{Relato dos casos}

\section{Sintomatologia clínica}

Foram atendidos pelo serviço de Enfermidades Infecciosas dos Animais da FMVZ/UNESPBotucatu-SP, no período de janeiro a julho de 2001, quatro animais com sintomatologia compatível com toxoplasmose. Os animais apresentavam apatia, tosse e ataxia. Na anamnese constatou-se histórico de ingestão de carne crua e deficiência ou ausência de imunoprofilaxia contra cinomose.

Dois dos quatro animais coabitavam com gatos, enquanto um tinha contato com cães com história pregressa de sintomas neurológicos. Dois cães tinham acesso à rua e um era proveniente de ambiente rural.

Ao exame clínico constataram-se principalmente sinais de pneumonia, linfadenopatia, esplenomegalia e secreção ocular purulenta.

Ao exame neurológico, todos animais apresentavam ataxia, com a dismetria por hipermetria constituindo o achado mais freqüente. Foram observados déficits proprioceptivos principalmente de membros posteriores e também caracterizados por trançar de membros anteriores, queda durante a deambulação e alteração de consciência. Ao exame de nervos cranianos, o déficit de oculomotor revelou ser mais freqüente, evidenciado por uma resposta pupilar anormal ao estímulo luminoso, presente nos quatro animais. Em somente um caso, observaram-se diminuições das respostas de olfatório, troclear e trigêmeo, evidenciadas, respectivamente, por anosmia, estrabismo dorso-medial e insensibilidade facial. Os animais apresentavam normalidade de reflexos patelares e ausência de sensibilidade medular.

\section{Exames complementares}

Os achados hematimétricos à admissão revelaram anemia em três animais, que variou de normocítica normo/hipocrômica a microcítica normocrômica, associada a linfopenia (Tabela 1). Exames bioquímicos revelaram aumento na atividade sérica de alanina amino transferase (ALT) e creatinina quinase (CK), além de hiperglobulinemia em três casos e hipoglobulinemia em um dos animais (Tabela 2). A análise de líquor foi realizada em dois animais, apresentando hiperglicorraquia, citologia com predomínio de linfócitos e presença 
de globulinas no líquido cefalorraquiano, evidenciada pelo teste de Pandy.

O teste sorológico de imunofluorescência indireta (IFI) para toxoplasmose (CAMARGO, 1974) constitui um método auxiliar específico para o diagnóstico da enfermidade. Utilizando-se a IFI, observou-se sorologia crescente para 1/256 entre as amostras pareadas em dois animais, título de $1024 \mathrm{em}$ um cão e de 16384 em outro, evidenciando-se a toxoplasmose nos quatro casos relatados. Do animal com sorologia 16384, realizou-se a IFI para toxoplasmose a partir do líquor, obtendo-se título 64.

Dois dos animais tiveram a indicação de eutanásia. Após a necropsia, procedeu-se à colheita dos encéfalos e pulmões. Os pulmões foram submetidos à digestão com solução ácida de pepsina (DUBEY, 1998). O mesmo processamento foi realizado com os encéfalos. Este procedimento com posterior inoculação em camundongos, resultou no isolamento de $T$. gondii.

O diagnóstico de cinomose foi firmado a partir dos dados clínico-epidemiológicos aliados aos achados dos exames hematimétricos e citológicos (detecção da inclusão de Sinigaglia-Lentz) e constatado em três dos casos relatados.

\section{Tratamento}

A terapia dos animais consistiu em antimicrobianos de amplo espectro (cloranfenicol 50 $\mathrm{mg} / \mathrm{kg}$ SC ou sulfonamídicos $50 \mathrm{mg} / \mathrm{kg}$ associados com trimetoprim $10 \mathrm{mg} / \mathrm{kg}$ ). Adicionalmente, realizou-se terapia de suporte com reposição do equilíbrio hidroeletrolítico e energético (fluido glicofisiológico ${ }^{\mathrm{f}}$ para os animais sem diarréia e Ringer-lactato ${ }^{f}$ glicosado a $3 \%$ para os com diarréia), vitamina $\mathrm{C}^{\mathrm{a}}$ (500mg), complexo $\mathrm{B}^{\mathrm{b}}(2 \mathrm{ml})$. Com a confirmação da sorologia positiva para toxoplasmose mudou-se o tratamento antimicrobiano para a associação de sulfadoxina/sulfametoxazol com trimetoprim $^{\mathrm{c}}$. Após 7 dias do início desta terapêutica os animais recebiam suplementação dietética com ácido fólico $(5 \mathrm{mg}) \mathrm{d}$.

No animal 2 (Tabela 1), ao final de 15 dias de início da terapia, substitui-se a associação de sulfonamídicos com trimetoprim para a associação ${ }^{e}$ com pirimetamina. Os animais foram tratados por 30 dias e no final deste período avaliou-se a necessidade de continuação do tratamento mediante avaliação clínica e de exames complementares, incluindo hemograma completo, testes bioquímicos e sorologia para toxoplasmose. Dois animais apresentaram agravamento do quadro clínico, mesmo com início da terapia, sendo indicada a eutanásia (animal 3 e 4). O animal 2, com título 16384, recebeu alta após 60 dias de tratamento. Este animal apresentou títulos sorológicos semanalmente decrescentes, embora tenha permanecido com um pequeno grau de dismetria devido à seqüela neurológica. $\mathrm{O}$ animal 1 não apresentava cinomose associada e recebeu alta, também permanecendo com pequeno grau de dismetria.

\section{Discussão e Conclusões}

A presença dos achados de linfadenopatia, pneumonia e sinais neurológicos em cães com toxoplasmose, também tem sido destacada por outros autores como as principais manifestações clínicas da doença (ABREU et al., 1999b; DUBEY; BEATTIE, 1998). Adicionalmente, o histórico de ingestão de carne crua, livre acesso à rua e coabitação com felinos, associados à ocorrência de sintomas pulmonares e neurológicos, devem chamar a atenção do clínico para o diagnóstico de toxoplasmose (BRAUND, 1986). Entretanto, diferentes entidades nosológicas devem

f Labormédica

a Hipolabor

b EMS (10mg B1, 2,5 mg B2; 2,5 mg B6, 6mg Pantenol, 30 mg Nicotinamida)

c Borgal (Hoechst Roussel Vet); Bactrim (Roche)

d Folin (Geyer)

e Fansidar (Roche) 
ser consideradas no diagnóstico de cães com sintomatologia nervosa. Dentre estas doenças de origem infecciosa, assume destaque a cinomose, visto que os sintomas neurológicos determinados por esta enfermidade são indistinguíveis da toxoplasmose em cães (NELSON; COUTO, 1994).

A co-infecção de três dos casos relatados, com o vírus da cinomose, caracterizada pela presença de corpúsculos de inclusão viral em leucócitos e em órgãos, certamente favoreceu a ação patogênica de T. gondii, que se caracteriza como agente oportunista, tanto em animais como no homem (SILVA et al., 1997; CANTOS et al., 2000; TENTER; HECKEROTH; WEISS, 2000). A presença de baixos títulos sorológicos na prova de imunofluorescência indireta para toxoplasmose deve ser inicialmente interpretada como indicativo de infecção, em face do alto risco de contato dos animais com o agente. Entretanto, no presente estudo, observou-se a soroconversão dos animais em amostras pareadas, bem como títulos considerados altos para toxoplasmose na espécie, caracterizando estado de doença nos animais relatados (DUBEY; BEATTIE, 1998).
Na vigência de co-infecção em cães por $T$. gondii e pelo vírus da cinomose, ou na impossibilidade de estabelecer-se o diagnóstico diferencial entre estas enfermidades, recomenda-se a terapia com sulfonamídicos e trimetoprim. A farmacocinética destas drogas propicia níveis terapêuticos nos tecidos sujeitos à infecção bacteriana decorrente da cinomose e também no SNC, devendo-se utilizar a associação com objetivo de obtenção de amplo espectro antibacteriano e adicional combate ao Toxoplasma.

Mesmo diante da alta prevalência de cinomose em cães comparativamente à manifestação clínica de toxoplasmose na espécie (TIPOLD; VANDEVELDE; JAGGY,1992), com base nos animais estudos, ressalta-se a crescente necessidade da inclusão da toxoplasmose no diagnóstico diferencial de cães com sintomas pulmonares e/ou nervosos. Esta abordagem etiológica torna-se importante, visto que a eficácia terapêutica nos casos de cinomose já é considerada baixa, alcançando elevada letalidade quando da ocorrência simultânea destes dois agentes em cães.

Tabela 1 - Achados laboratoriais em quatro cães infectados por Toxoplasma gondii, com sinais neurológicos. Botucatu, 2001.

\begin{tabular}{|c|c|c|c|c|c|c|c|c|c|c|}
\hline \multirow{2}{*}{$\begin{array}{l}\text { Animal } \\
\text { Parâmetros avaliados }\end{array}$} & & \multicolumn{2}{|l|}{1} & \multicolumn{3}{|c|}{2} & \multicolumn{2}{|l|}{3} & \multicolumn{2}{|l|}{4} \\
\hline & & \multicolumn{9}{|c|}{ Hemograma } \\
\hline \multicolumn{11}{|l|}{ Hematimetria } \\
\hline Hemácias $\left(\mathrm{X} 10^{6} / \mu \mathrm{l}\right)$ & 5,72 & 5,76 & 6,08 & 4,99 & 3,94 & 4,06 & 4,58 & 4,70 & 4,29 & 4,43 \\
\hline Hemoglobina (g/dl) & 13,5 & 13,8 & 14,2 & 10,6 & 9,8 & 9,7 & 10,6 & 11,7 & 11,1 & 10,5 \\
\hline Volume globular (\%) & 38 & 38 & 39 & 35 & 28 & 28 & 29 & 33 & 32 & 31 \\
\hline VGM (fl) & - & - & - & 70,1 & 71 & 68,9 & 63,3 & 70,2 & 74,5 & 69,9 \\
\hline CHCM (\%) & - & - & - & 30,2 & 35 & 34,6 & 36,5 & 35,4 & 34,6 & 33,8 \\
\hline \multicolumn{11}{|l|}{ Leucometria } \\
\hline Leucócitos $\left(\mathrm{X} 10^{3} / \mu \mathrm{l}\right)$ & 29,5 & 26,7 & 20,5 & 22,3 & 20,9 & 14,8 & 6,9 & 7,2 & 3,6 & 9,3 \\
\hline Neutrófilos $\left(\mathrm{X} 10^{3} / \mu \mathrm{l}\right)$ & 5,31 & 4,53 & 3,69 & 20,3 & 17,3 & 12,5 & 5,6 & 5,6 & 3,2 & 9,1 \\
\hline Linfócitos $\left(\mathrm{X} 10^{3} / \mu \mathrm{l}\right)$ & 23,6 & 20,5 & 15,9 & 0,22 & 0,61 & 0,44 & 0,2 & 0,6 & 0 & 0,2 \\
\hline Monócitos $(\mathrm{X} 1 / \mu \mathrm{l})$ & 295 & 801 & 410 & 0 & 204 & 592 & 1035 & 936 & 324 & 0 \\
\hline Eosinófilos $(\mathrm{X} 1 / \mu \mathrm{l})$ & 295 & 801 & 410 & 1788 & 2244 & 1184 & 0 & 0 & 0 & 0 \\
\hline
\end{tabular}


Tabela 2 - Parâmetros bioquímicos em quatro cães com toxoplasmose com sinais neurológicos. Botucatu, 2001.

\begin{tabular}{|c|c|c|c|c|c|c|c|c|c|c|}
\hline Animal & & 1 & & & 2 & & 3 & & 4 & \\
\hline Parâmetros avaliado & & \multicolumn{9}{|c|}{ Perfil bioquímico } \\
\hline \multicolumn{11}{|l|}{ Função Renal } \\
\hline Uréia (mg/dl ) & 53,3 & 40,5 & - & 50,4 & 25,2 & 63,6 & - & - & - & 26,4 \\
\hline Creatinina (mg/dl) & 0,6 & 0,7 & - & 0,6 & 0,9 & 0,9 & - & - & - & 1,1 \\
\hline \multicolumn{11}{|l|}{ Função Hepática } \\
\hline ALT (UI/L) & 51,9 & 207,9 & - & 78 & 21,5 & 68,1 & - & - & - & 25,7 \\
\hline FA $\quad(\mathrm{UI} / \mathrm{L})$ & 16,6 & 23,6 & - & 123,5 & 62,2 & 124,5 & - & - & - & 70 \\
\hline GGT (Ul/L) & - & 15,5 & - & 4,1 & 4,1 & 7 & - & - & - & 2 \\
\hline PST $(g / d L)$ & 8,4 & 9,4 & - & - & 10,2 & 7,4 & - & - & - & 4,02 \\
\hline ALB $(\mathrm{g} / \mathrm{dL})$ & 3,7 & 3 & - & - & 2,8 & 2,6 & - & - & - & 2,48 \\
\hline GLO $(g / d L)$ & 4,7 & 6,4 & - & - & 7,4 & 4,8 & - & - & - & 1,54 \\
\hline CPK (mg/dl) & - & - & - & 259,8 & - & 786,8 & - & - & - & 803,8 \\
\hline
\end{tabular}

\section{Referências}

ABREU, C.B. et al. Toxoplasmose ocular em cães experimentalmente inoculados com Toxoplasma gondii. In: ENCONTRO NACIONAL DE PATOLOGIA VETERINÁRIA, 9., 1999, Belo Horizonte. Anais... Belo Horizonte, 1999a. p.71.

ABREU, C.B. et al. Achados anatomopatológicos da toxoplasmose experimental em cães jovens. In: ENCONTRO NACIONAL DE PATOLOGIA VETERINÁRIA, 9., 1999, Belo Horizonte. Anais... Belo Horizonte, 1999b. p.51.

BRAUND, K.G. Toxoplasmosis. In: Clinical syndromes in veterinary neurology. Baltimore: Willians \& Wilkins, 1986. cap.3, p.173-4.

BRESCIANI, K. D. S.et al. Clinical, parasitological and obstetric observations in pregnant bitches with experimental toxoplasmosis. Ciência Rural, Santa Maria, v.31, n.6, p. 1039-43, 2001.

BRITO, A. F.et al. Epidemiological and serological aspects in canine Toxoplasmosis in Animals with nervous symptoms. Memórias do Instituto Oswaldo Cruz, Rio de Janeiro, v.97, p.1-5, 2002.
CAMARGO, M. E. Introdução às técnicas de imunofluorescência. Revista Brasileira de Patologia Clínica, Rio de Janeiro, n.10, p.143-69, 1974.

CANTOS, G. A. et al. Toxoplasmose: ocorrência de anticorpos antiToxoplasma gondii e diagnóstico. Revista da Associação Médica Brasileira, São Paulo, v.46, n.4, p.335-341, 2000.

CORRÊA, W. M.; CORRÊA, C. N. M. Toxoplasmose. In: __ Enfermidades infecciosas dos mamíferos domésticos. Rio de Janeiro: Medsi, 1992. p.757-766.

DUBEY, J. P. Refinement of pepsin digestion method for isolation of Toxoplasma gondii from infected tissues. Veterinary Parasitology, Amsterdam, v.74, p.74-7, 1998.

Toxoplasma, hammondia, besnoitia, sarcocystis and other tissue cyst-forming coccidia of man and animals. In: KREIER, J. P. Parasitic protozoa. New York: Academic Press, 1977. v.3, cap.4, p.101-71.

DUBEY, J. P.; BEATTIE, C. P. Toxoplasmosis in dogs (Canis familiaris). In: _ Toxoplamosis of animals and man. Boca Raton: CRC Press, 1998. cap.8, p.127-42. 
DUBEY, J. P.; LAPPIN, M. R. Toxoplasmosis and neosporosis. In: GREENE, C. E. Infectious diseases of the dog and cat. 2.ed. Philadelphia: WB Saunders Company, 1998. Cap. 90, p.493-503.

GERMANO, P. M. L.; ERBOLATO, E. B.; ISHIZUKA, M. M. Estudo sorológico da toxoplasmose canina, pela prova de imunofluorescência indireta, na cidade de Campinas, 1981. Revista da Facultade de Medicina Veterinária e Zootecnia da Universidade de São Paulo, São Paulo, v.22, n.1, p.53-58, 1985.

GUIMARÃES, A. M. et al. Frequiência de anticorpos anti-Toxoplasma gondii em cães de Belo Horizonte, Minas Gerais. Arquivos Brasileiros de Medicina Veterinária e Zootecnia, Belo Horizonte, v.44, n.1, p.67-68, 1992.

ISHIZUKA, M. M.; YASUDA, P. H. Incidência de infecção por Toxoplasma gondii em cães do município de São Paulo. Revista da Faculdade de Medicina Veterinária e Zootecnia da Universidade de São Paulo, São Paulo, v.18, n.2, p.161-165, 1981.

KAWAZOE, U. Toxoplasma gondii. In: NEVES, D. P. et al. Parasitologia humana. 9.ed. São Paulo: Atheneu, 1995. Cap.16, p.174-87.

MARTIN, C. L.; STILES, J. Ocular Infections. In: GREENE, C. E. infectious diseases of the dog and cat. 2.ed. Philadelphia: WB Saunders Company, 1998. cap. 93, p.658-72.
MARTINS, C. S.; VIANA, J. A. Toxoplasmose : o que todo profissional de saúde deve saber. Clínica Veterinária, São Paulo, n.15, p.33-7,1998.

NAVARRO, I. T. et al. Estudo comparativo entre soro e plasma na pesquisa de anticorpos anti-Toxoplasma gondii pela técnica de imunofluorescência indireta em cães atendidos no hospital veterinário da Universidade Estadual de Londrina-PR, 1996. Semina: Ciências Agrárias, Londrina, v.18, n.1, p.15-21, 1997.

NELSON, R. W.; COUTO, C. G. Encefalite/mielite/ meningite. In: Fundamentos de medicina interna de pequenos animais. Rio de Janeiro: Guanabara Koogan, 1994. cap.70, p.566-71.

SILVA, D. O.et al. Detection of Toxoplasma gondiispecific antibodies in dogs: a comparative study of immunoenzymatic, immunofluorescent and haemagglutination titers. Memória do Instituto Oswaldo Cruz, Rio de Janeiro, v.92, n.6, p.785-789, 1997.

TENTER, A. M.; HECKEROTH, A. R.; WEISS, L. M. Toxoplasma gondii: from animals to humans. International Journal for Parasitology, Elmsford, n.30, p.1217-58, 2000.

TIPOLD, A.; VANDEVELDE, M. ; JAGGY, A. Neurological manifestations of canine distemper infection. Journal of Small Animal Practice, Gloucestershire, v.33, p. 466-70, 1992.- 